\title{
Nonlinear Seismic Performance Evaluation of Flexural Slotted Connection Using Endurance Time Method
}

\author{
Seyed Mohamad Seyed Kolbadi (D), ${ }^{1}$ Hosein Piri (D), ${ }^{2}$ Ali Keyhani ${ }^{2},{ }^{2}$ \\ S.Mahdi Seyed-Kolbadi $\mathbb{D}^{3},{ }^{3}$ and Masoud Mirtaheri $\mathbb{i D}^{3}$ \\ ${ }^{1}$ Department of Civil Engineering, Technical and Vocational University (TVU), Tehran, Iran \\ ${ }^{2}$ Department of Civil Engineering, Shahrood University of Technology, Shahrood, Iran \\ ${ }^{3}$ Department of Civil Engineering, K. N. Toosi University of Technology, Tehran, Iran \\ Correspondence should be addressed to Seyed Mohamad Seyed Kolbadi; s_seyyedkolbadi@sbu.ac.ir
}

Received 1 July 2020; Revised 2 October 2020; Accepted 12 November 2020; Published 9 December 2020

Academic Editor: Fidelis Tawiah Suorineni

Copyright (c) 2020 Seyed Mohamad Seyed Kolbadi et al. This is an open access article distributed under the Creative Commons Attribution License, which permits unrestricted use, distribution, and reproduction in any medium, provided the original work is properly cited.

\begin{abstract}
The equivalent statistical methods, spectral analysis, and time history analysis are usually offered in the steel structure design regulations. Among these methods, the third one is more accurate; however, it requires more time to align the accelerometers due to a large number of analyses. In the endurance time (ET) method, incremental acceleration functions gradually and uniformly increases over time while their linear and nonlinear response spectra are proportional to the mean of the real seismic spectrum. These functions are used as input functions to analyze the nonlinear time history of structures, and the performance of structures is evaluated based on the maximum length of time they can meet specified performance goals. A three-story steel bending frame with (slotted web) SW and (web unslotted flange) WUF connection is examined through the performance time method in performance-based design. This article aimed at evaluating the seismic performance of these connections in the bending frame through endurance time analysis to predict the structural response in the probabilistic evaluation of the seismic performance of the structures. It is found that the endurance time analysis is justified with the seismic performance of the connections with low computational cost and proper accuracy. The results of comparing both SW and WUF connections indicated that the SW connection prevents the connection welding area from being failed due to transferring the plastic joint into the beam and in an area away from the column face and causes less damage compared to the WUF connection.
\end{abstract}

\section{Introduction}

After the 1994 Northridge earthquake [1] and the connection failure in the weld zone of the beam-to-column connection [2], the researchers sought to transfer the location of the plastic joint at a suitable distance from the column face [3]. Two solutions were proposed as strengthening the beam-to-column connection area $[4,5]$ or weakening the beam area to move the plastic joint into the beam [6]. The weakening of the beam was used by creating two grooves in the beam to transfer the plastic joint into the beam and reducing the tension and strain of beam-to-column welding area and the column panel area is used. Regarding the postearthquake damage, assessing the safety of structures against collapse is considered an important task in earthquake engineering. Seismic collapse refers to the inability of structural systems to resist under gravitational loads or shortly after an earthquake [7]. This is classified into two main modes: the first is the progressive collapse mode due to spreading the local damage from one component to another until the destruction of the structures' strength. This type of collapse was surveyed in the study of Kim and Kim [8] and Liu [9].

The second mode is one-way collapse, which is the result of excessive lateral displacement of one or more floors of a structure, so much so that the effects of P- $\Delta$ on the shear strength of the structure prevail. Some studies were conducted by Villaverde, Ligenus, and Kravinkler to evaluate the 
one-sided collapse of structures. In addition, the equivalent degree of freedom (SODF) was used by several researchers to predict initial collapse [10-12]. Although this method is very good for understanding the problem, it is not reliable enough to be used as a tool to assess the collapse capacity of structures. Using the single degree of freedom (SDOF) exhibits nonlinear behaviour when the structure is approaching the stage of collapse which does not have an appropriate answer [10]. Incremental dynamic analysis (IDA) [13] is considered a reliable tool with the ability to consider all nonlinear resources, including breakdown components due to dynamic loading [14]. Multidegree-offreedoms (MDOF) systems have recently been used to evaluate the collapse of structures [15, 16]. Attempts have also been made to estimate IDA results through pushover analysis $[17,18]$; however, the accuracy of these methods at this level of approximation requires a simple analytical method, which results in a comprehensive analysis of the behaviour of the structure from the beginning to the complete collapse of the structure [19].

The ET method has been used to evaluate the collapse capacity of structures to investigate both SW and WUF connections, and the seismic performance of the flexural connection is evaluated with the grooved damper in the frame through ET time analysis based on the methodology presented in FEMA-P58 [20]. As shown, a wide range of seismic engineering topics such as linear seismic analysis of steel bending frames [21], nonlinear seismic evaluation of steel bending frames [22], three-dimensional seismic analysis of structures [23], seismic evaluation of steel storage tanks [24], and performance-based design of structures [25] are performed satisfactorily in the ET method. ET is an alternative method among time-based approaches to seismic analysis of structures in which the structure is subjected to an increasingly dynamic stimulus whose intensity gradually increases over time [26].

The response of the structure is examined over time, and strengths, weaknesses, and performance of the structure are evaluated according to the corresponding response with different levels of stimulus intensity. Then, after presenting generalities of endurance time method, the way to produce accelerated functions, as well as the dimensions and specifications of the models created in the software, limited components, and modelling validation, the values of stress and strain created in the panel area and the beam-to-column connection area are examined in both WUF and SW connections.

\section{Basic Concepts of ET Analysis}

The concept of ET analysis can be better described by hypothetical shaking table testing. Three different structures with unknown structural characteristics have been constructed according to their seismic resistance function. All three structures are fixed on the seismic table, and the test initiates with a very low vibration amplitude on the structure, as shown in Figure 1(a). The test is performed with a gradual increase in the vibration range of the vibrating table. As the vibration amplitude increases, one of the structures is broken and the first point is obtained, as shown in Figure 1(b). As the vibration amplitude increases continuously, a point is reached when the second and third structures are fractured. This is shown in Figures 1(b) and $1(\mathrm{c})$. It is shown that the structures " $\mathrm{C}$ " and B are broken at $t=15 \mathrm{~s}$ and $t=20 \mathrm{~s}$, respectively. As the results indicated and that the lateral loads applied by the seismic table are in some way consistent with the earthquake loads, the " $A$ " structure, which was the earliest to be destroyed, is the worst sample in the rating and structure " $\mathrm{B}$ " with the longest loading time performs best in rankings. This hypothetical test describes the concept of endurance time. In the ET method, the structures are exposed to a predesigned accelerator and their performance is judged by the time interval, during which the structures can meet the predefined performance criteria, such as resistance against fracture in the above test [27]. The concept of ET is somewhat similar to the exercise test used by a cardiologist to assess the condition of the cardiovascular system of athletes or cardiovascular patients [28] (Figure 1).

In exercise tests, the subject is placed on a treadmill, and the speed and slope of the treadmill at each step gradually increase until the subject is fractured, or there are signs of distress or abnormal biological criteria. The condition of the person's cardiovascular system is then judged based on the number of steps performed. Then, an interpretation of the results obtained from the ET test should be prepared for practical programs. Since the structural models of finite element components of the prototypes used in the test are available and assuming that a suitable ET acceleration function is designed, the above test method can be repeated numerically. It seems that the reliable prediction of the structure's collapse is beyond the capability of most existing analytical software. However, other simple criteria can be used, such as maximum floor displacement or other factors that lead to damage instead of complex nonlinear analysis. In addition, choosing the appropriate performance criteria depends on the scope and purpose of the analysis [29]. For example, some linear criteria, such as maximum stress on members or maximum displacements, can be considered as limiting criteria for calculating the structural endurance time to survey the service load level [30].

Providing the right acceleration functions is considered the most important steps in achieving the goals of endurance time analysis. Endurance time acceleration functions are considered as the one whose demand increases steadily over time. One of the parameters that should be considered in preparing acceleration functions is the increasing trend of these functions [31]. As shown in Figure 2, this increase can take many forms, such as linear increase, ascending rate, or decreasing rate. It is possible to choose the right form according to the results obtained from the analysis. The linear form is considered as the basic form [32], as shown in Figure 3.

The accelerogram recorded in a natural earthquake has three main characteristics such as amplitude, the endurance of strong motion, and frequency content, which depend on the severity of the earthquake, its distance to the site of the desired structure, and the soil conditions of the site [33]. It is necessary that the above three factors be properly considered 
in the construction of the functions to bring the desired acceleration functions as close as possible to the accelerations obtained from natural earthquakes [34]. As mentioned, acceleration functions have an increasing range of accelerations. Therefore, the range of functions should increase in such a way that represents weak earthquakes at low times and strong earthquakes at high times. The persistence of strong acceleration functions has an increasing trend due to increasing their amplitude over time. However, the persistence of strong motion in real earthquakes is a constant number and also varies in different earthquakes [35]. The third parameter is the frequency content of the acceleration functions. If this content is within a certain range, the results will not be accurate for different structures. Since the frequency content of different earthquakes is different, choosing the appropriate frequency content depends on the site. The frequency content of acceleration functions is directly related to how they are produced [36].

\section{Materials and Methods}

3.1. Numerical Study. The endurance time (ET) method is a dynamic structural analysis procedure for seismic assessment of structures. In this procedure, an intensifying dynamic excitation is used as the loading function. Endurance time method is a time history-based dynamic analysis procedure. An estimate of the structural response at different equivalent seismic intensity levels is obtained in a single response history analysis. This method has applications in seismic assessment of various structural types and in different areas of earthquake engineering. Endurance time (ET) method is a dynamic structural analysis procedure in which intensifying dynamic excitation is used as the loading function. An estimate of structural response and/or performance at the entire seismic intensity range of interest is obtained in each response history analysis. The concept of endurance time analysis is similar to the exercise test applied in medicine. A similar concept has also been extended to applications in the analysis of offshore platforms under water waves.

The dynamic analysis is a higher level of structural statistical analysis due to the variability of relations. In structural dynamics analysis, an input dynamic load, such as an earthquake load, is applied as the baseload to the structure, and the output of quantities such as stress and strain is shown in the diagrams that result from this loading called the time history chart. The nonstratified random sampling method is used in the amplitude and frequency content to provide first-order acceleration functions [22]. In this method, the stimulus function is obtained as a sum of several different harmonic functions from equation (1). Also, in the endurance time method, the dynamic performance of structures was evaluated mainly based on horizontally artificial records.

$$
a(t)=\sum_{i=1}^{N} A_{i} \cdot \sin \left(\omega_{i} t+\varnothing_{i}\right) .
$$

This equation represents the Fourier scope of the $i^{\text {th }}$ sentence, $\Phi_{i}$ is the phase delay angle of $i^{\text {th }}$ the sinusoidal component, $\omega_{i}$ indicates the angular frequency of $i^{\text {th }}$ sentences, and $n$ is the number of sentences [3]. If the set of phases and angles of phase delay related to the sinusoidal components are considered as the amplitude vector and phase delay angle vector, various movements which are similarly based on frequency content are produced by keeping the amplitude vector constant and then producing different phases of phase delay vector. The function produced in this way is a static function [37]. The acceleration functions are generated by random numbers with a Gaussian distribution with a mean of zero and a variance. The time step is 0.01 seconds and the number of points of the acceleration function is $211=2048$, equivalent to 20.48 seconds (Figure 3). The maximum ground acceleration at this stage is assumed to be $1 \mathrm{~g}$.

The function obtained in the previous step is static, while the acceleration caused by natural earthquakes is of an abnormal nature. To convert the above steady function to an unsteady function, it should be multiplied by the appropriate envelope function. This envelope function should be appropriate to the severity of the earthquake and its distance to the desired location. For example, an appropriate envelope function (equation (2)) is shown in Figure 4.

$$
Z(t)=f(t) \cdot a(t) .
$$

In the acceleration function obtained, it is necessary to filter the unnatural frequencies in such a way as to eliminate their effect on the analysis of the time history. For this purpose, the Fourier conversion of the $Z(t)$ function should be obtained and multiplied by two filter functions such as the following equations:

$$
\begin{aligned}
Z(i \omega) & =F(Z(t)), \\
A(i \omega) & =Z(i \omega) \cdot H_{1}(i \omega) \cdot H_{2}(i \omega), \\
H_{1}(\overline{i \omega}) & =\frac{1+2 i \xi_{1}\left(\bar{\omega} / \omega_{1}\right)}{\left(1-\left(\overline{\omega^{2}} / \omega_{1}^{2}\right)\right)+2 i \xi_{1}\left(\bar{\omega} / \omega_{1}\right)}, \\
H_{2}(\overline{i \omega}) & =\frac{\left(\bar{\omega} / \omega_{1}\right)^{2}}{\left(1-\left(\overline{\omega^{2}} / \omega_{2}^{2}\right)\right)+2 i \xi\left(\bar{\omega} / \omega_{2}\right)}, \\
A^{\text {new }}(i \omega) & =A^{\text {old }}(i \omega) \cdot \frac{S_{a}^{T}(\omega)}{S_{a}(\omega)}
\end{aligned}
$$

In the above equations, $F$ indicates the intermediate conversion and $A(i \omega)$ acceleration in the frequency range. Considering $\omega_{1}=2 \pi / 0.5$ and $\omega_{2}=2 \pi / 0.1$ and $\xi_{1}=\xi_{2}=0.2$, the values of the frequencies higher than the Nyquist $(100 \mathrm{HZ})$ are filtered (Figure 5).

Then, the frequency content has been changed to match the spectrum of the regulations so that there is a criterion for subsequent analyses following the regulations. To comply with the range of regulations (related to soil type II), $A(i \omega)$ function is taken to the time domain by converting the 

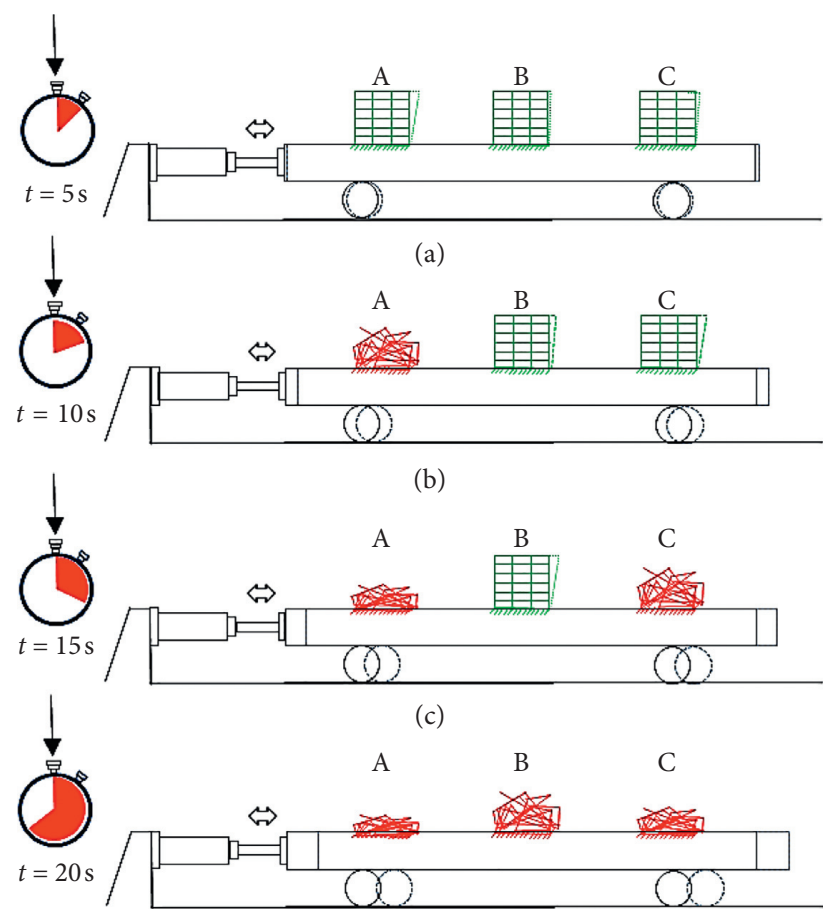

(d)

FIgURE 1: Hypothetical shaking table test.

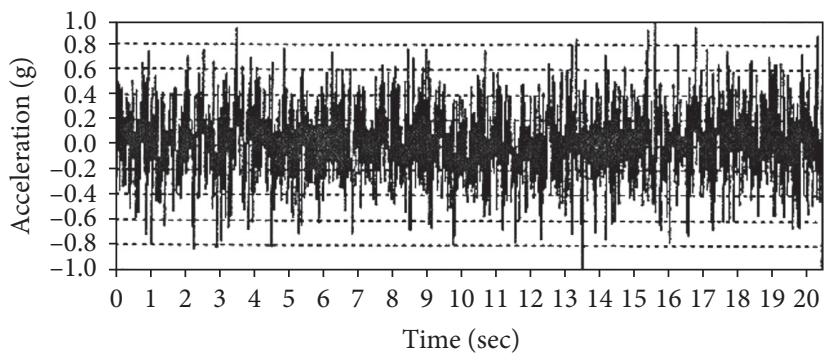

FIgUre 2: Acceleration function with Gaussian distribution $(\mathrm{PGA}=1)$.
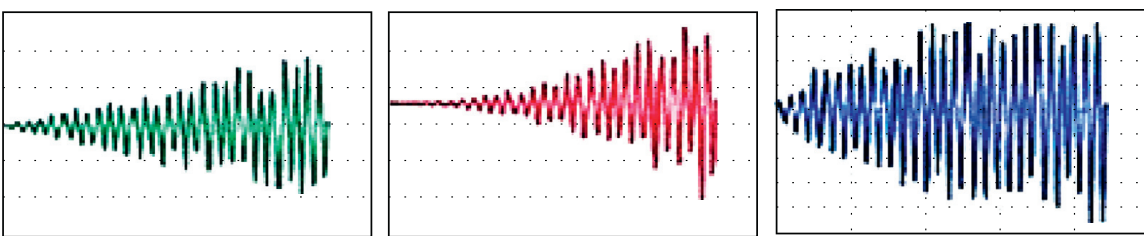

FIgURE 3: Different forms of demand increase in acceleration functions.

inverse Fourier to the time domain and the acceleration function $a(t)$ is obtained. The response spectrum of this function is obtained and compared with the spectrum of the regulation. $A^{\text {old }}(i \omega)$ is the acceleration Fourier conversion, $S_{a}^{T}(\omega)$ represents the target range, and $S_{a}(\omega)$ indicates the response range of the acceleration function in the previous section. Finally, the inverse conversion $A^{\text {new }}(i \omega)$ is calculated to take the acceleration function over a period of time. Therefore, the new acceleration function is obtained, which is more compatible with the spectrum of the regulations. To get closer to the response spectrum of the acceleration function and the spectrum of the regulations, the final steps are repeated several times to achieve the desired accuracy. In this equation, the relationship between the Fourier conversion and linear response spectrum is assumed. In addition, nonlinear relationships are used to accelerate convergence. The modified frequency content is shown in Figure 6.

The acceleration functions are then modified to create acceleration and zero speed at the endpoints. Finally, by selecting the linear increment form, $f(t)=(t / 10)$ linear function in the acceleration function, multiply by 10 seconds 


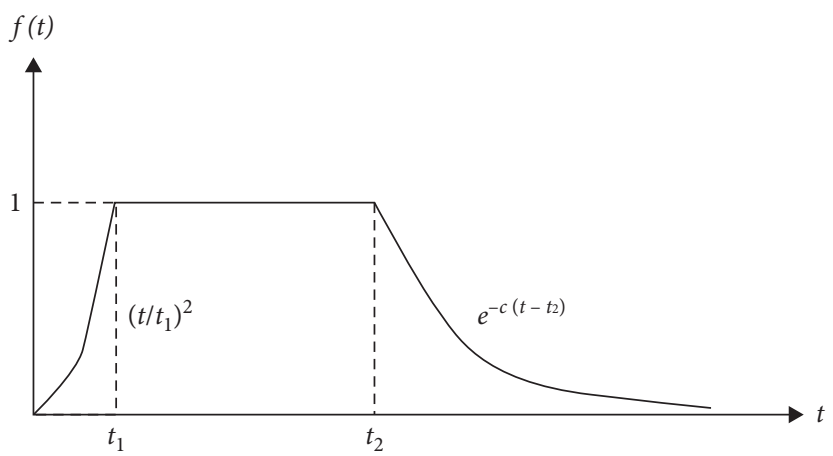

FIgURE 4: $f(t)$ density function to create unsteady function.

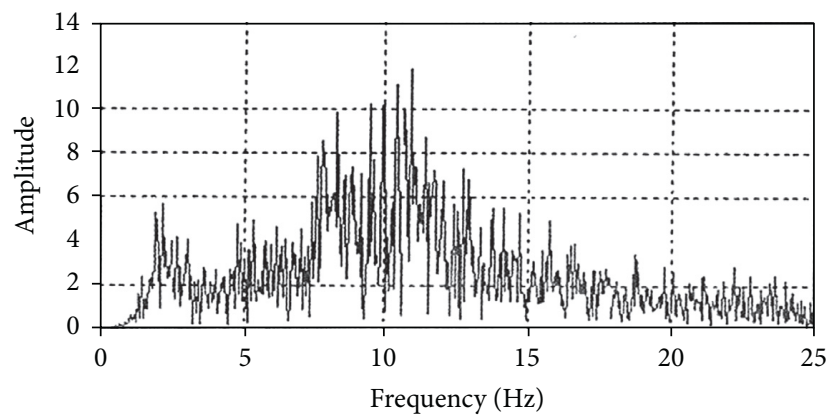

Figure 5: Filtered frequency content.

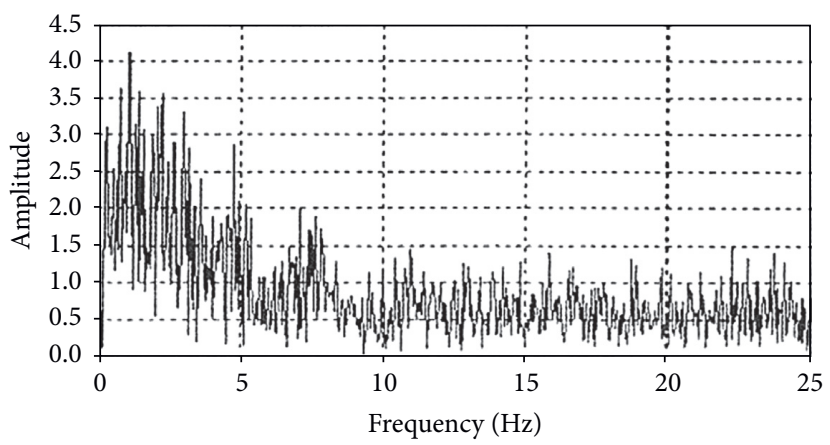

FIGURE 6: Frequency content in accordance with the design spectrum.

to check the results. At this stage, the three functions of incremental acceleration acc1, acc2, and acc3 are produced, as shown in Figure 7.

3.2. Configuration of Models. Modelling in a frame similar to Figure 8 has been performed in Abacus's finite element software according to the geometric details of Table 1 for two samples, SW and WUF. ST37 steel with 8-shape specifications has been used for the models created in this article. The displacement for the two ends of the column along with U_1 is considered to be zero. The loading according to the ET method, similar to what obtained in Figure 9, is applied to the model at the buckling points. For the meshing, the Hex/ Structured mesh (with Solid element, 8 knots with reduced integral; C3D8R) is used. To achieve a suitable mesh, the partitioned model has been transformed into simple shapes so that it can use both structured mesh and better control over the mesh. Using solid elements compared to Shell elements indicates better results in large deformations and has better accuracy. The mesh size varies from 3 to $15 \mathrm{~cm}$ in the sample.

A finer mesh is used in the areas around the hole created at the end of the beam groove to more accurately obtain the SW connection behaviour [39]. Figure 10 shows the method of applying boundary conditions at the end of the column and loading in both SW and WUF models. In this connection, models with geometric details shown in Table 1 are used. In the WUF model, a shear was used to strengthen the beam, with dimensions of $222 \times 80 \times 158 \times 10 \mathrm{~mm}$. In 


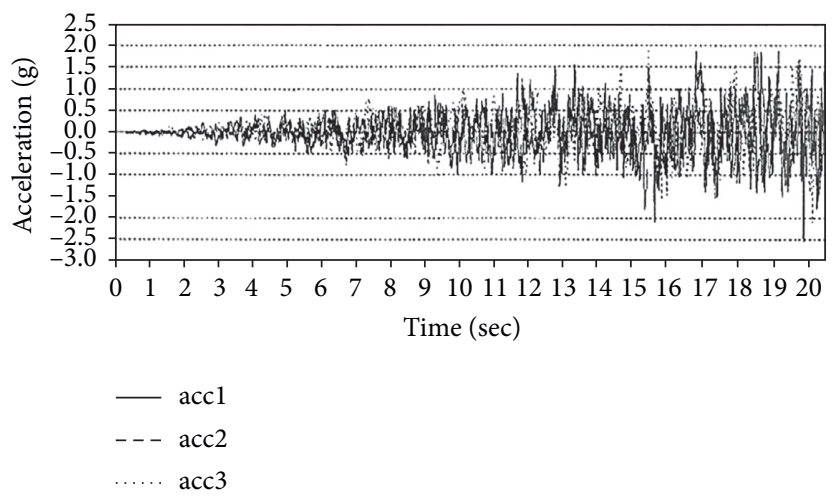

Figure 7: First series acceleration functions.

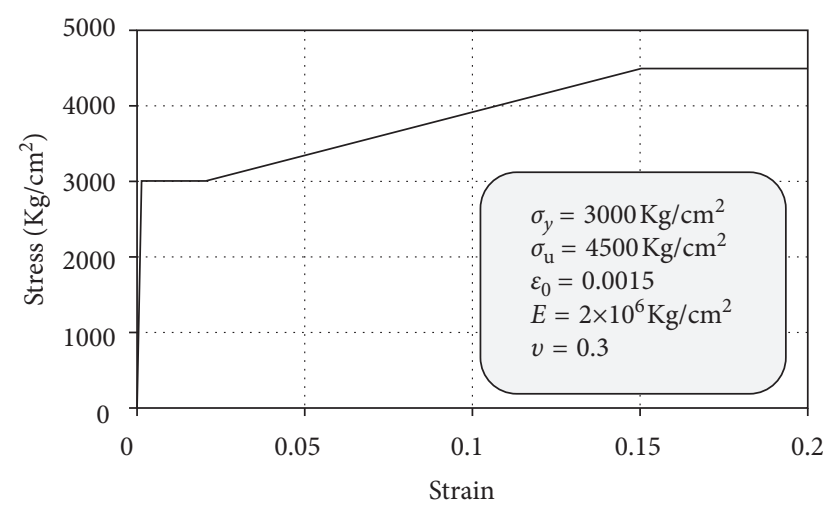

FIGURE 8: Stress-strain diagram of the experimental specimen [3].

TABLE 1: Modelled subassembly (units in $\mathrm{mm}$ ).

\begin{tabular}{|c|c|c|c|c|c|c|}
\hline Connection & & Cross section & Steel grade & Column height & Beam length & Sheet dimension \\
\hline \multirow{2}{*}{ SW and WUF } & Beam & IPE270 & ST37 & & 1300 & \\
\hline & Column & Plate girder & ST37 & 630 & $\ldots$ & $\mathrm{W} 630 \times 190 \times 10 / \mathrm{F} 630 \times 220 \times 15$ \\
\hline
\end{tabular}

addition, a cutter has been used to strengthen the $80 \mathrm{~mm}$ long, $190 \mathrm{~mm}$ diameter beam in the SW model and vertical stiffeners with dimensions of $1 \times 4 \times 5 \times 7 \mathrm{~cm}$ have been used to strengthen the beam wing. Since it is necessary to create a groove in the beam to weaken the beam in the modelling of the grooved connection, the following equation has been used to calculate the dimensions of the beam:

$$
L_{s}=\min \left\{1.5 b_{f}, 0.60 t_{\mathrm{bf}} \sqrt{\frac{E}{F_{\mathrm{ye}}}}, \frac{d}{2}, L_{p}+\frac{L_{b}-L_{p}}{10}\right\}
$$

where $L_{b}, L_{p}, d, f_{\mathrm{ye}}, t_{\mathrm{bf}}, b f$, and $L_{s}$, respectively, represent half the clear span length of the beam, the width of the shear plate, nominal depth of the beam, expected yield strength of steel beam, beam flange thickness, beam flange width, and slot length [40]. Considering the above equations, the length of the groove is $160 \mathrm{~mm}$ and the diameter of the end hole is $21 \mathrm{~mm}$.

3.3. Verification of Finite Element Modelling. To verify the accuracy of the modelling performed in this paper, the slotted connection created by Adlparvar et al. was examined in the laboratory [6], similar to Figure 11, which has been performed in finite element software according to the geometric details of Table 2. A simple anchor is assumed for the two ends of the column. In this model, the load is applied at a distance of $1 \mathrm{~m}$ from the column and a shear connector is used to strengthen the beam with a length of $80 \mathrm{~mm}$ and a width of $190 \mathrm{~mm}$. In addition, vertical stiffeners with dimensions of $1 \times 4 \times 5 \times 7 \mathrm{~cm}$ have been used to strengthen the beam wing. The column and beam web stiffeners were used, and the place of beam web stiffener is exactly where the 


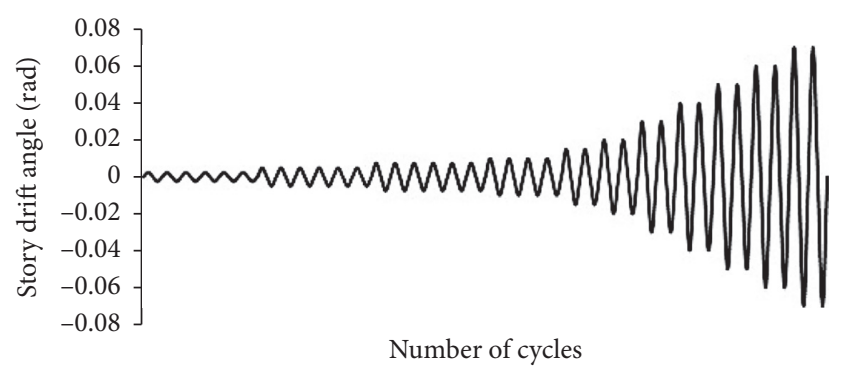

Figure 9: Loading history [38].

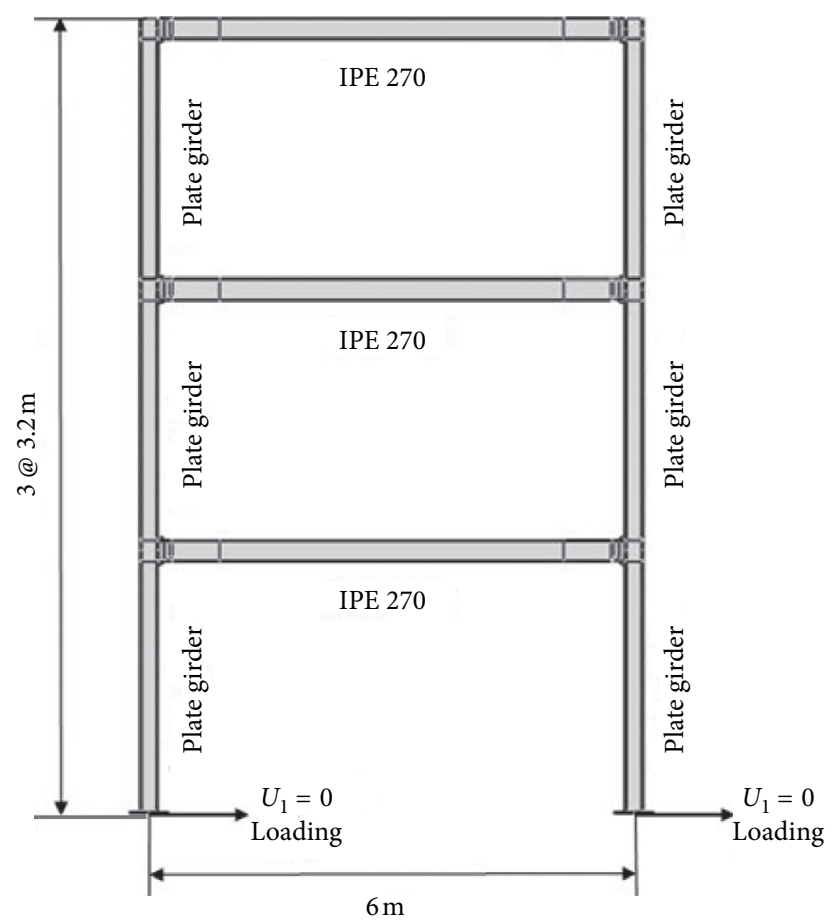

Figure 10: Three-story modelled frame.

load is applied and its dimensions are $24.96 \times 6.42 \times 1 \mathrm{~cm}$. In addition, the length of the beam's web groove is $160 \mathrm{~mm}$ and the diameter of its end hole is $21 \mathrm{~mm}$. Also, the model configuration in this paper is the same as in [6] with some modifications in implementing slotted connection in it.

Since many models have been used for the response surface method, the Shell element has been used to make the calculations faster. A mesh with a quad-dominated structure (SA4) has also been used to mesh. For a proper meshing with partitioning, the model has been transformed into simple shapes so that better control over the mesh can be achieved. The size of the meshes for modelling in the response surface method is considered as small as possible to increase the accuracy of the calculations. In modelling, the mesh size varies from 0.5 to $1 \mathrm{~cm}$.

After analysis, the local buckling and the plastic joints formed in the simulated model are similar to what occurred during the experiment and the hysteresis diagram of the laboratory sample was compared to the simulated model as shown in Figure 12.
The maximum force applied to Adlparvar et al.'s numerical model is $200.85 \mathrm{KN}$, which occurs at a rotation of $3.43 \%$, while in the modelling created in the same rotation of the beam, the maximum displacement is 209.61 since the maximum difference is less than $5 \%$. Therefore, the numerical model response is valid and the numerical model can be used to investigate the parameters of this study.

\section{Results and Discussion}

To better understand the performance of WUF and SW connections, these connections are subjected to dynamic loads. The earthquake data processing software (SiesmoSignal) has been used to apply the loading of the ET method to the structure in a time-displacement manner as shown in Figure 13, and the results of these models are shown in Figure 14.

As shown in Figure 14, the stress distribution in the last second of loading of the welding zone has a more 


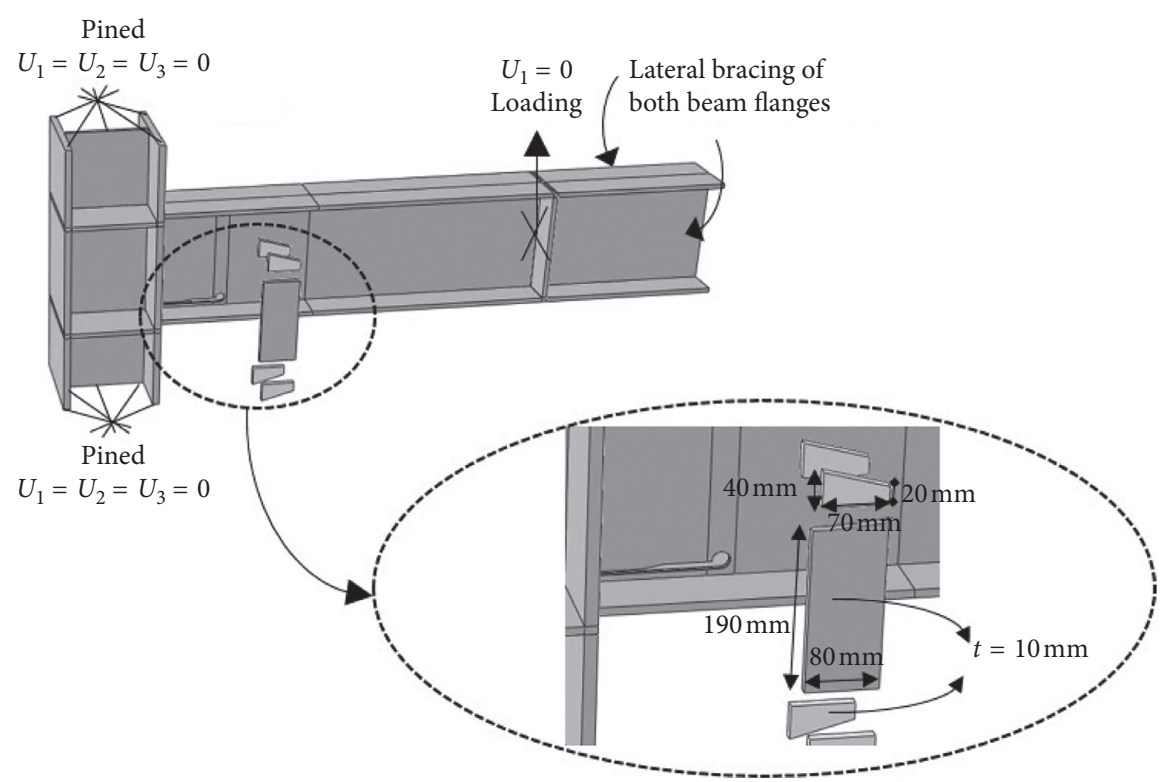

FIGURE 11: SW geometry (units in $\mathrm{mm}$ ).

TABLE 2: Modelled subassembly (units in $\mathrm{mm}$ ).

\begin{tabular}{|c|c|c|c|c|c|c|}
\hline Connection & & Cross section & Steel grade & Column height & Beam length & Sheet dimension \\
\hline \multirow{2}{*}{ Slotted web } & Beam & IPE270 & ST37 & $\ldots$ & 1300 & \\
\hline & Column & Plate girder & ST37 & 630 & $\ldots$ & $\mathrm{W} 630 \times 190 \times 10 / \mathrm{F} 630 \times 220 \times 15$ \\
\hline
\end{tabular}

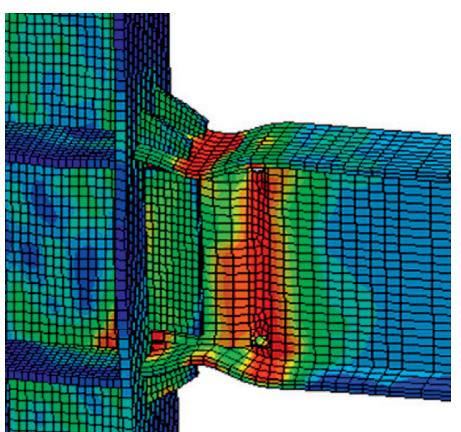

(a)

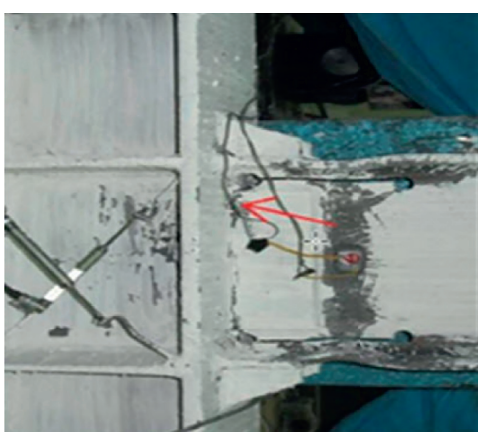

(b)

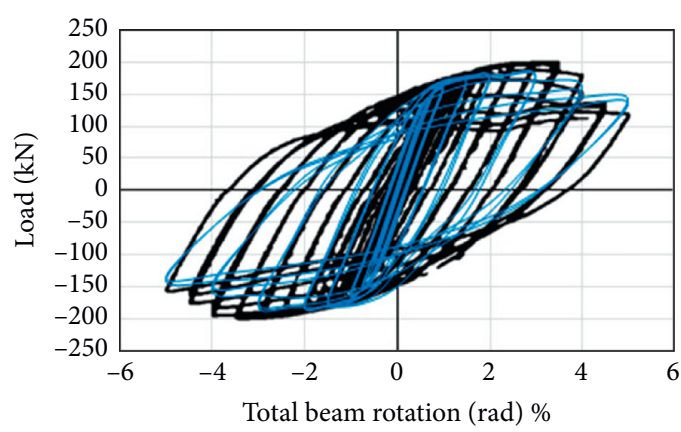

(c)

FIGURE 12: Comparison of the FE model and test results of specimen SW tested by [6]. (a) Test [3]. (b) Modelled specimen. (c) Hysteresis responses.

uniform value in the SW connection than that of the WUF connection. In addition, creating a groove in the beam web of the SW connection reduced the stress values in the column's panel area. The results comparing the maximum strain in the beam-to-column connection area, fountain spring area, and the modelled frames are shown in Figure 15, where PEEQ strain and MISES stress are used.

As shown in Figure 15, the lowest amount of strain in the panel area and the weld strength of the beam-column connection occurred in SW and WUF joints, respectively, where the amount of strain in the panel area is 0.25 and $0.4 \%$, respectively, and the lowest strain value and the lowest amount of strain at the welding point of the beamto-column connection are 0.37 and $0.59 \%$, respectively. Figures 16 and 17 use the Misses stress, which is used to better understand and compare the behaviour of the specimens in the Grade 2 equation diagram.

Figures 16 and 17 show that the maximum amount of stress created in the panel area and the weld area of the beam-to-column connection in the modelled SW connection is less than the WUF. In addition, the maximum stress in the SW and WUF connection panel area is 299 and $378 \mathrm{~kg} / \mathrm{m}^{2}$, respectively, and the stress at the SW and WUF connection welds is 297 and $318 \mathrm{~kg} / \mathrm{m} 2$, 


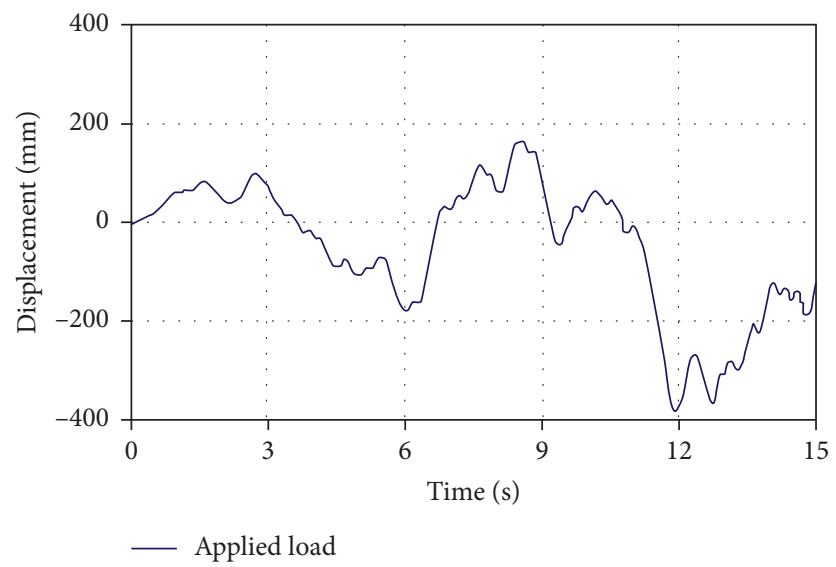

FIGURE 13: Loading history.

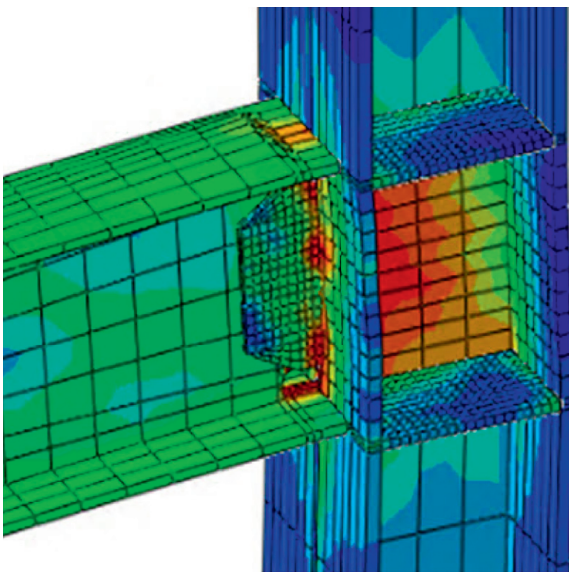

(a)

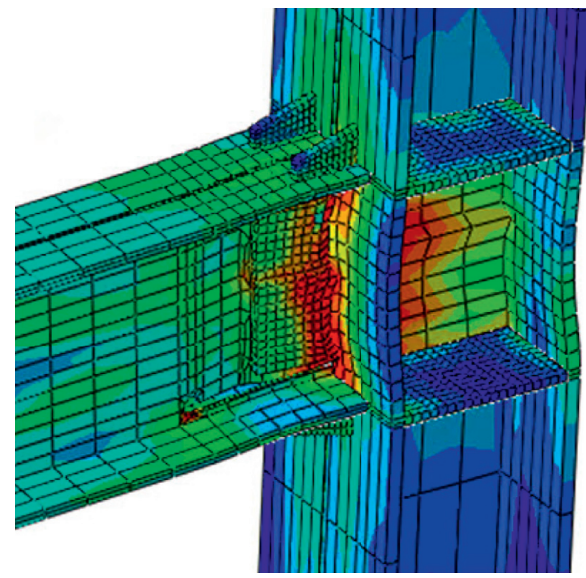

(b)

Figure 14: WUF (a) and SW (b) connections in the frame.

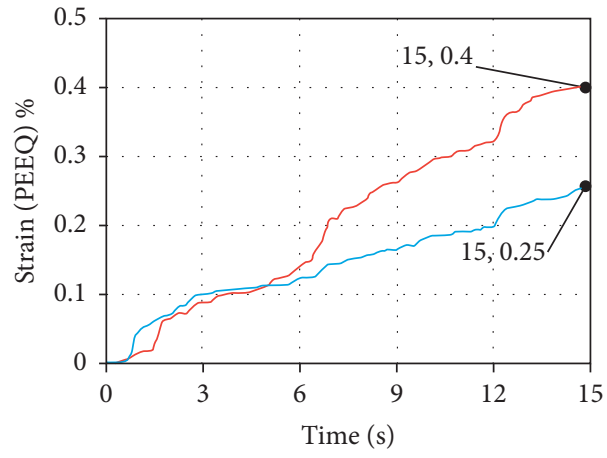

— WUF

- SW

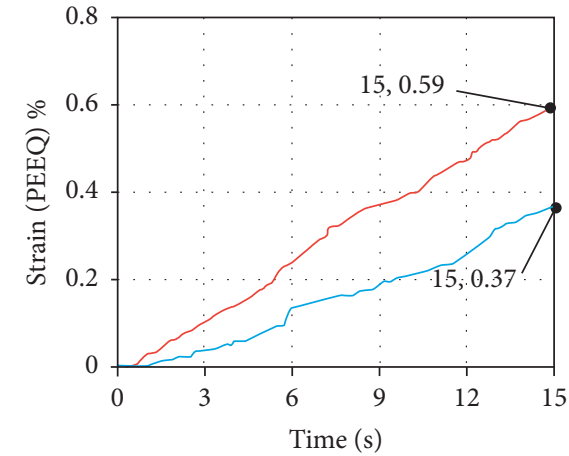

— WUF

(a)

(b)

FIgURE 15: The strain in the connection panel zone (a) and the weld area of the beam to the column connection (b) 


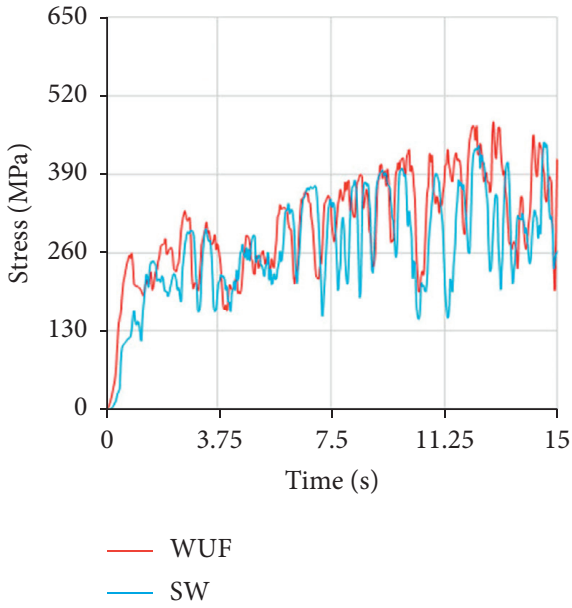

(a)

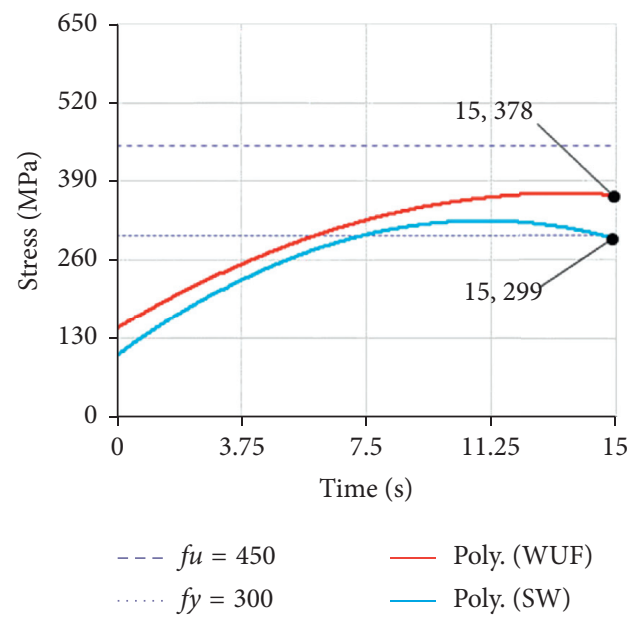

(b)

FIGURE 16: The stress in the connection panel zone (a) and the weld area of the beam to the column connection (b)

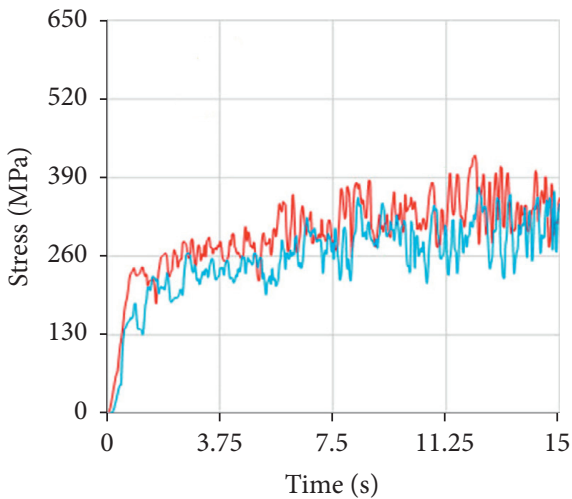

- WUF
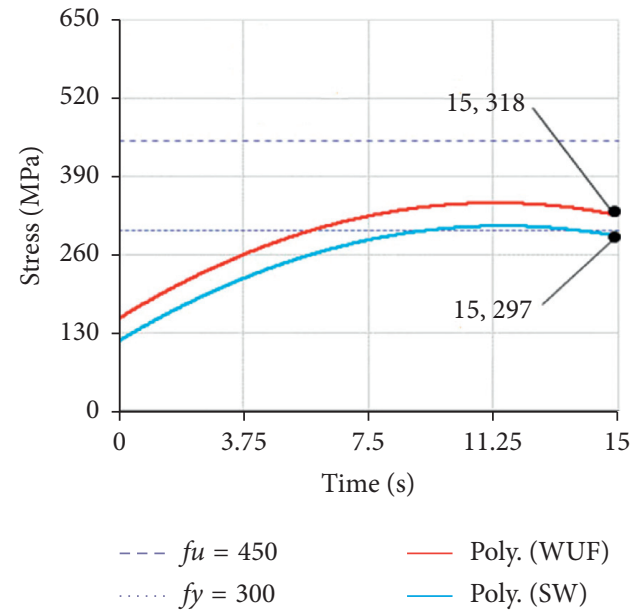

(b)

FIGURE 17: The stress at the weld area of the beam to the column connection in the connection panel zone (a) and the weld area of the beam to the column connection (b)

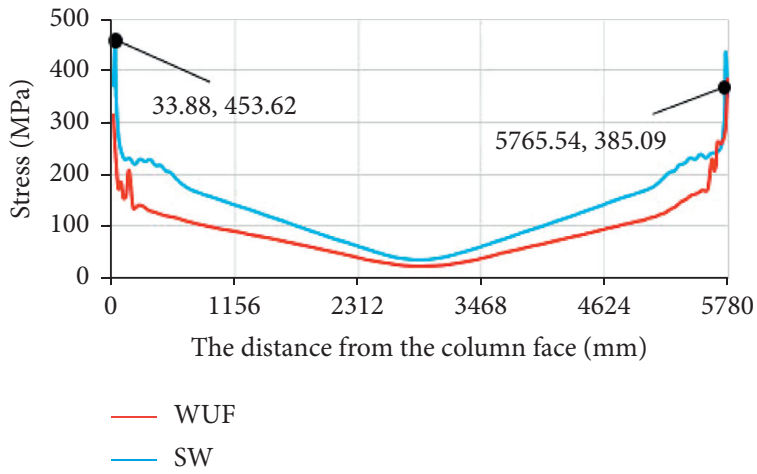

(a)

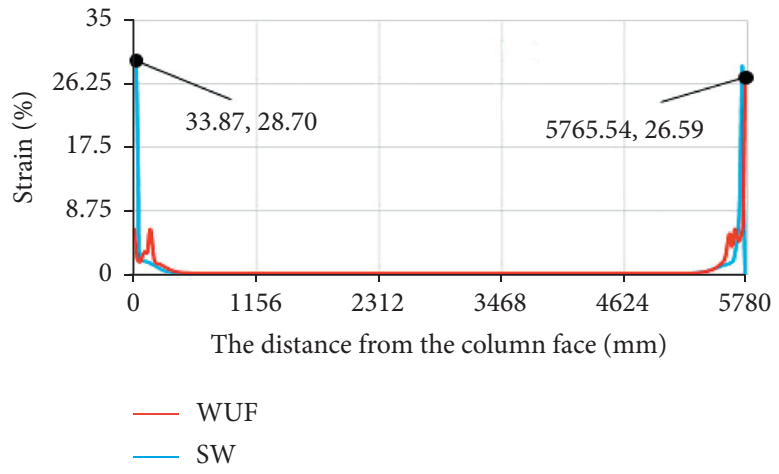

(b)

FIgURE 18: Continued. 


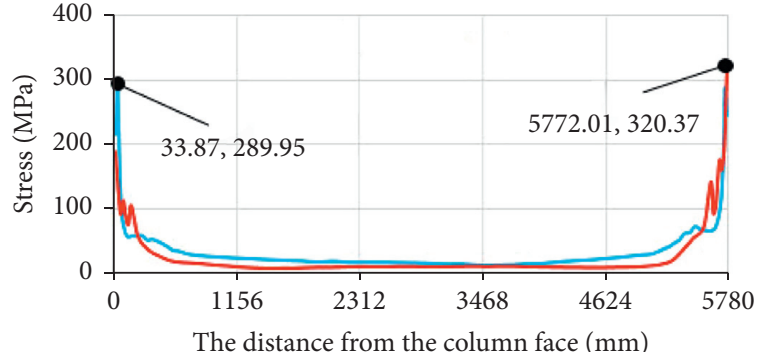

- WUF

_ SW

(c)

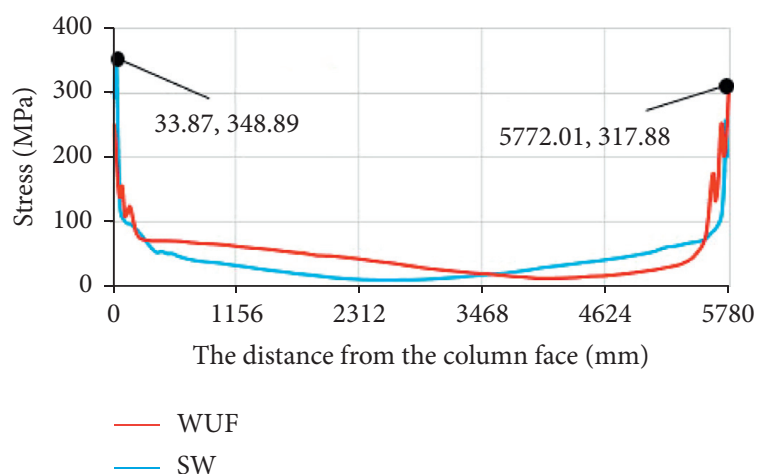

(e)

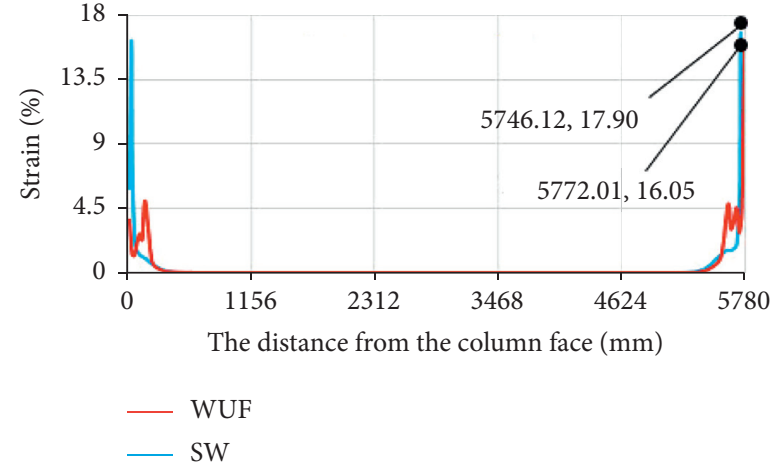

(d)

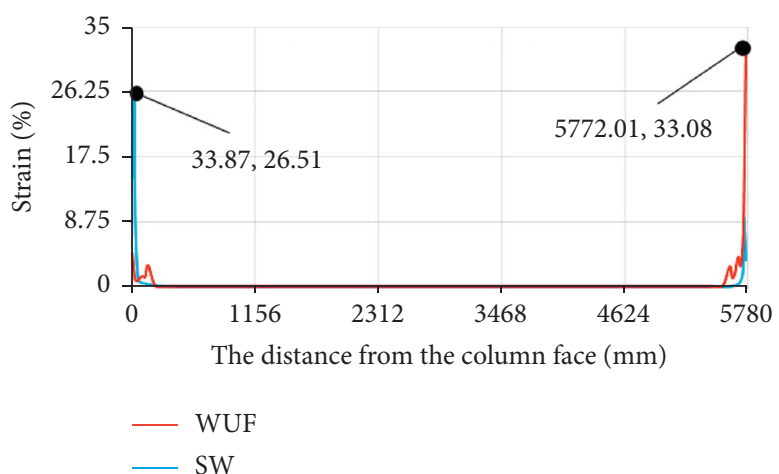

(f)

FigURE 18: The values of stress and strain on SW and WUF along the beam in a three-story frame $(t=15 \mathrm{~s})$. (a) First story beam stress. (b) First story beam strain. (c) Second story beam stress. (d) Second story beam strain. (e) Third story beam stress. (f) Third story beam strain.
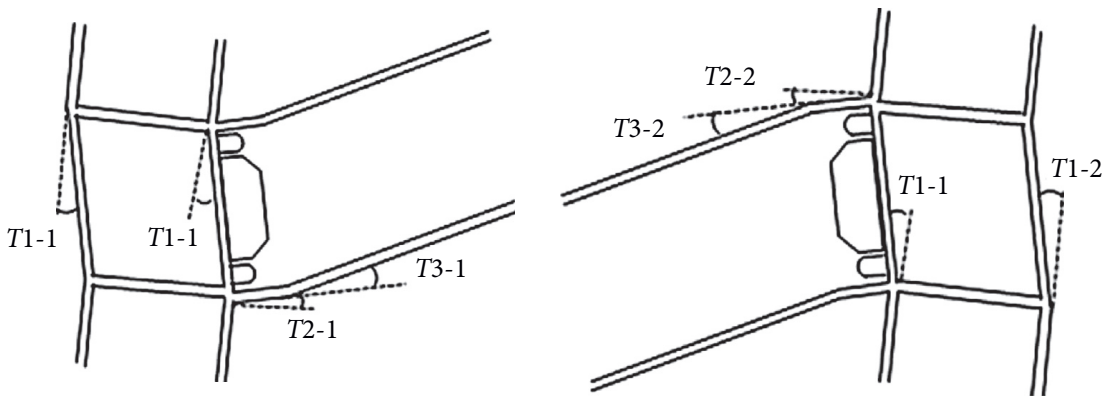

(a)
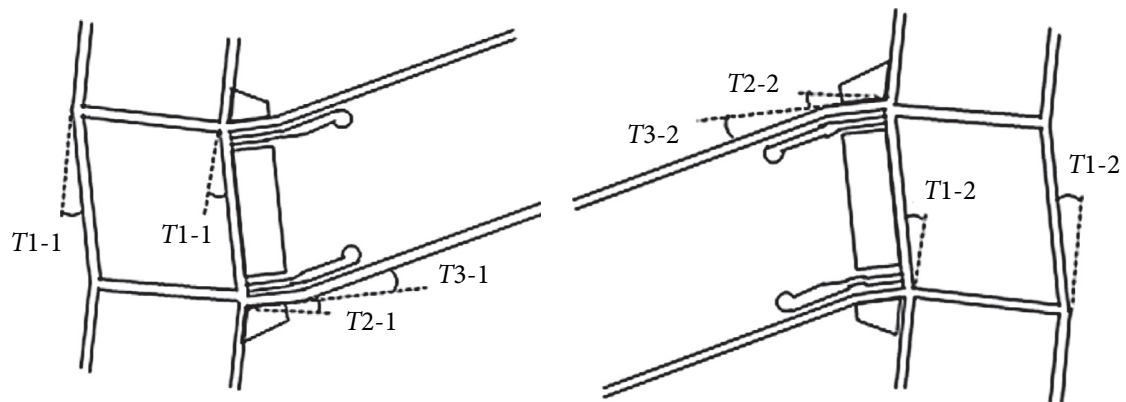

(b)

FIgURE 19: Continued. 

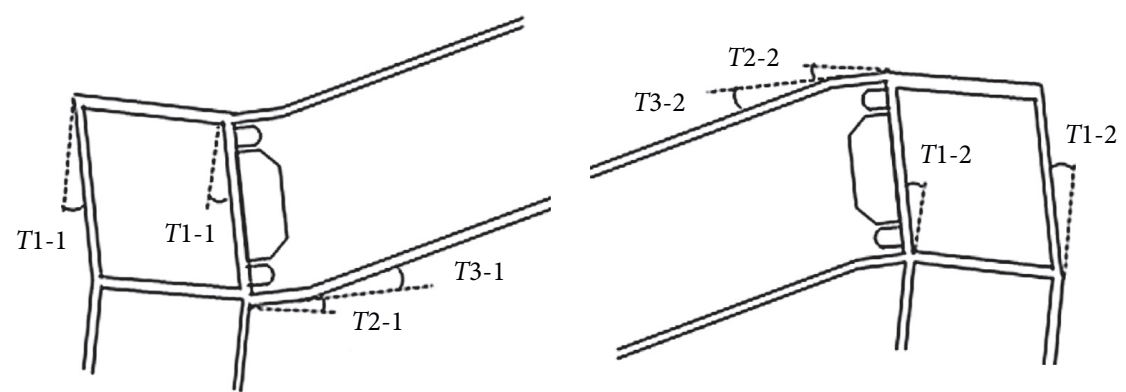

(c)
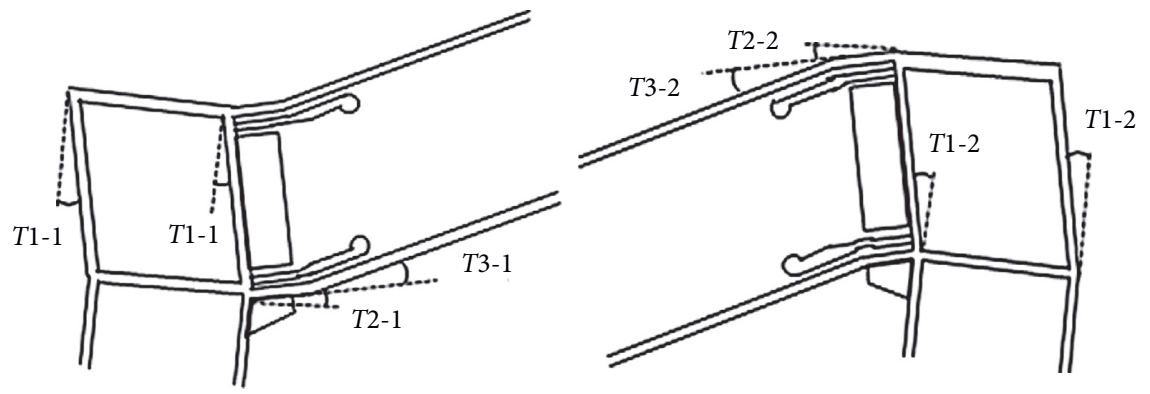

(d)

Figure 19: The values of rotation on SW and WUF in a three-story frame ( $t=15 \mathrm{~s})$. (a) The rotation of the two ends of the beam in the WUF connection on the first and second stories. (b) The rotation of the two ends of the beam in the SW connection on the first and second stories. (c) The rotation of the two ends of the beam in the WUF connection on the third story. (d) The rotation of the two ends of the beam in the SW connection on the third story.

TABLE 3: The values of rotation on SW and WUF (units in rad).

\begin{tabular}{|c|c|c|c|c|c|c|c|}
\hline \multirow{2}{*}{\multicolumn{2}{|c|}{ Type of connection }} & \multicolumn{2}{|c|}{ Panel zone rotation } & \multicolumn{2}{|c|}{$\begin{array}{l}\text { Beam rotation (rotate } \\
\text { the beam near the side } \\
\text { of the column) }\end{array}$} & \multicolumn{2}{|c|}{$\begin{array}{c}\text { Beam rotation (rotate } \\
\text { the beam farther } \\
\text { from the column } \\
\text { face) }\end{array}$} \\
\hline & & $\mathrm{T}_{1-1}$ & $\mathrm{~T}_{1-2}$ & $\mathrm{~T}_{2-1}$ & $\mathrm{~T}_{2-2}$ & $\mathrm{~T}_{3-1}$ & $\mathrm{~T}_{3-2}$ \\
\hline \multirow{2}{*}{ First story } & WUF & 0.15 & 0.16 & 0.05 & 0.06 & 0.18 & 0.18 \\
\hline & SW & 0.17 & 0.16 & 0.06 & 0.003 & 0.18 & 0.19 \\
\hline \multirow{2}{*}{ Second story } & WUF & 0.17 & 0.16 & 0.14 & 1.63 & 0.19 & 0.18 \\
\hline & SW & 0.16 & 0.03 & 1.63 & 0.14 & 0.18 & 0.18 \\
\hline \multirow{2}{*}{ Third story } & WUF & 0.18 & 0.17 & 0.06 & 0.005 & 0.2 & 0.19 \\
\hline & SW & 0.17 & 0.06 & 0.005 & 0.03 & 0.19 & 0.15 \\
\hline
\end{tabular}

respectively. To better compare both SW and WUF connections, the stress and strain values along the beam on each floor of the modelled frame are examined and the results are shown in the following figures.

According to Figure 18, the values of stress and strain along the beam at the end of the loading time for the modelled SW connection are less than those of the WUF connection in most cases, leading to reducing earthquake damage to the structure, as well as lower stress and strain values near the beam-to-column connection at the SW connection than those of the WUF connection prevent the beam-to-column connection failure in the weld zone.

It is worth noting that the areas of the SW connection in which the values of stress and strain are higher than WUF are due to the weakening of the beam's web since creating grooves in the beam causes the uniform distribution of tension and strain in the weld area of the beam. Since the grooves in the beam's web cause a uniform distribution of stress and strain in the weld area of the beam wing in the column and panel area as well as the better performance of the SW connection, this amount is ignored. In addition, the rotation values of the two ends of the beam and the rotation of the column panel area on each floor have been investigated in two SW and WUF connections, which are shown in Figure 19 and Table 3. Additionally, it is predicted that there would be a difference between the rotation values obtained for the beam-to-column connection and the beam's rotation in an area away from the beam-to-column connection due to the stiffness in the areas close to the joint. Therefore, the rotation values are considered in both areas. The values T_1, T_2, and T_3 are shown to be equal to the rotation of 


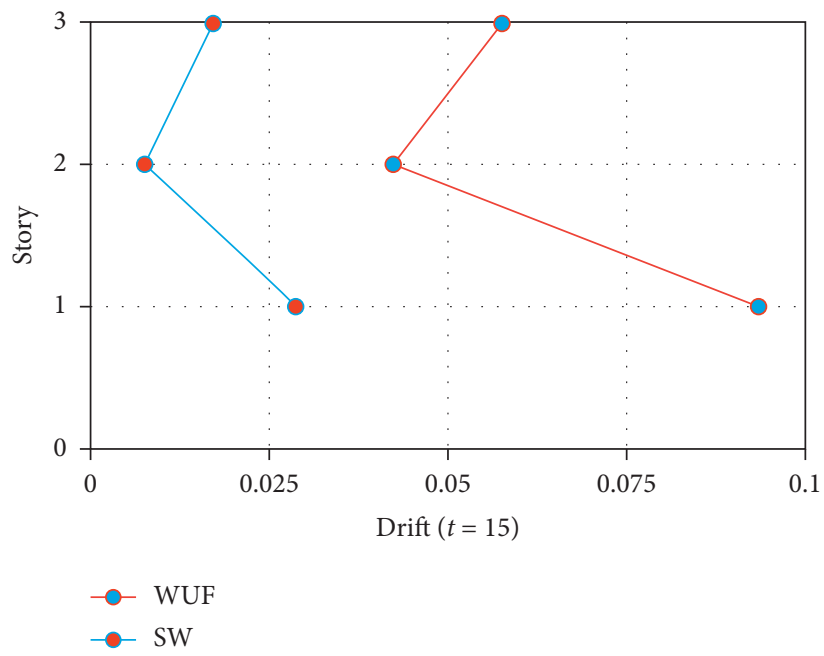

FIgURE 20: Story drift at target time $t=15 \mathrm{~s}$.

the panel area, the rotation of the beam at the connection area of the beam to the column, and the rotation of the beam in the area away from the connection area of the beam to the column, respectively.

Comparison of the rotation of the two ends of the beam and the rotation of the column panel area for the two SW and WUF connections found that the SW connection performs better due to the shorter period of time than the WUF connection. In modelling to increase the speed of model analysis, dynamic loading was applied to the frame, once considering the mass scale and once without considering the mass scale to obtain the appropriate size for mass scale. Based on the modelling, the appropriate mass scale for the modelled frames is considered $5 \times 10^{-5}$.

Since the mass scale is used in modelling to increase the speed of model analysis, the speed of loading on the loading side has increased. Therefore, the values of the displacements obtained on the backside of the loading were used to get the values of the structural drift. The results of the drift obtained from modelling a three-story frame are shown in Figure 20. Since the mass scale is used in modelling to increase the speed of model analysis, the loading speed on the loading side has increased. Therefore, to obtain the values of structural drift, the values of displacements obtained on the backside have been used for loading. The results of the drift obtained from modelling a three-story frame are shown in Figure 20.

Figure 20 shows the drift SW connection is less than WUF connection, in which the values for SW to WUF ratio on the first, second, and third floors are $69.27 \%, 82.1 \%$, and $70.07 \%$, respectively.

\section{Conclusions}

The WUF seismic steel bending connection and an SW connection consisting of a reduced section in the beam and two vertical beams wing hardeners were subjected under the dynamic load obtained by the ET method and the results are compared. The performance results indicated that the SW connection performs better than the
WUF connection. The two vertical stiffeners of the beam wing strengthen the beam wing and the connection area, and the reduced section in the beam acts as a fuse, forming the plastic joint in the beam and away from the column face, allowing uniform stress distribution in the weld zone to connect the beam to the column. This uniform distribution of stress in the weld zone of the beam-to-column connection reduces or eliminates the damage in the weld zone of the beam-to-column connection. The results indicated that

(i) Using the SW connection compared to the WUF connection reduces the maximum amount of equivalent plastic strain in the panel area after the completion of dynamic loading by $37.5 \%$ in 15 seconds, while the equivalent plastic strain in the weld zone of the beam-to-column connection decreased by $37.3 \%$.

(ii) Using the SW connection compared to the WUF connection reduces the maximum amount of table tension in the panel area after dynamic loading in 15 seconds by $20.9 \%$, while in the same period, table tension in the weld zone of the beam-to-column connection is reduced by $6.6 \%$.

(iii) Using the SW connection instead of the WUF connection reduces the tension in the panel area and the weld area of the beam-to-column connection due to the distance of the plastic joint formation from the column side; however, since the SW connection web is reduced by creating a weak groove, it leads to reducing the connection strength.

(iv) Using the SW connection reduces the amount of equivalent plastic strain created during the beam relative to the WUF connection, so that the maximum size of the equivalent plastic strain created along the beam for the SW connection to the WUF connection on the first and second floors decreases by $1 \%$ and $2 \%$, respectively while the amount of strain equivalent to the third floor has increased by 
$21.01 \%$, which is due to the weakening of beam's web. Since it keeps the plastic joint away from the column, it prevents premature damage to the beamto-column connection and ultimately improves connection performance.

(v) Using an SW connection reduces the amount of table tension created along the beam relative to the WUF connection, so that the maximum size of the Misses tension created during the beam to connect the SW to the WUF connection on the first and third floors decreases by $15.10 \%$ and $8.86 \%$, respectively. Meanwhile, the amount of Misses stress for the second floor has increased by $10.49 \%$ due to creating grooves along the beam and the weakening of the beam. Since this reduction in the beam's web reduces the stress in the weld area of the beam-tocolumn connection, it ultimately improves the connection performance.

(vi) Using an SW connection instead of a WUF connection reduces the rotation at the end of the loading time at both ends of the beam and in the panel area.

(vii) Using an SW connection instead of a WUF connection reduces the structural drift so that the drift decreased by $69.27 \%, 82.1 \%$, and $70.07 \%$ on the first, second, and third floors, respectively.

\section{Data Availability}

The data used to support the findings of the study are available from the corresponding author through e-mail (s_seyyedkolbadi@sbu.ac.ir).

\section{Conflicts of Interest}

The authors declare that there are no conflicts of interest regarding the publication of this paper.

\section{References}

[1] S. Maleki and M. Tabbakhha, "Numerical study of SlottedWeb-Reduced-Flange moment connection," Journal of Constructional Steel Research, vol. 69, no. 1, pp. 1-7, 2012.

[2] R. M. Richard, C. J. Allen, and J. E. Partridge, "Proprietary slotted beam connection designs," Modern Steel Construction, pp. 28-33, 1997.

[3] M. G. Vetr, "Effect of vertical flange stiffener on the ductility of slotted web exclusive connection on (I)-shape profiles through experimental investigation," Journal of Engineering Research, vol. 3, no. 4, 2015.

[4] S.-J. Chen, C. H. Yeh, and J. M. Chu, "Ductile steel beam-tocolumn connections for seismic resistance," Journal of Structural Engineering, vol. 122, no. 11, pp. 1292-1299, 1996.

[5] N. Fanaie, S. Kazerani, and S. Soroushnia, "Numerical study of slotted web drilled flange moment frame connection," Journal of Constructional Steel Research, vol. 69, no. 1, pp. 1-7, 2014.

[6] M. R. Adlparvar, M. G. Vetr, and F. Ghaffari, “The importance of panel zone shear strength on seismic behavior of improved slotted-web beam connections," International Journal of Steel Structures, vol. 17, no. 1, pp. 307-318, 2017.
[7] L. F. Ibarra and H. Krawinkler, Global Collapse of Frame Structures under Seismic Excitations," PEER Report No. 2005/ 06 Pacific Earthquake Engineering Research Center, University of California, Berkeley, CA, USA, 2005.

[8] J. Kim and T. Kim, "Assessment of progressive collapseresisting capacity of steel moment frames," Journal of Constructional Steel Research, vol. 65, no. 1, pp. 169-179, 2009.

[9] M. Liu, "Progressive collapse design of seismic steel frames using structural optimization," Journal of Constructional Steel Research, vol. 67, no. 3, pp. 322-332, 2011.

[10] R. Villaverde, "Methods to assess the seismic collapse capacity of building structures: state of the art," Journal of Structural Engineering, vol. 133, no. 1, pp. 57-66, 2007.

[11] D. G. Lignos and H. Krawinkler, "Sideway collapse of deteriorating structural systems under seismic excitations," Ph.D thesis, Report No. TB 172. Stanford (CA): John A. Blume Earthquake Engineering Research Center. Department of Civil and Environmental Engineering, Stanford University, Stanford, CA, USA, 2009.

[12] C. Adam, L. F. Ibarra, and H. Krawinkler, "Evaluation of P-delta effects in non-deteriorating MDOF structures from equivalent SDOF systems," in Proceedings of 13th World Conference on Earthquake Engineering, Vancouver, BC, Canada, August 2004.

[13] D. Vamvatsikos and C. A. Cornell, "Incremental dynamic analysis," Earthquake Engineering \& Structural Dynamics, vol. 31, no. 3, pp. 491-514, 2002.

[14] E. Mock and L. Cheng, "Performance of retaining walls with and without sound wall under seismic loads," Earthquakes and Structures, vol. 7, no. 6, pp. 909-935, 2014.

[15] C. B. Haselton and J. W. Baker, "Ground motion intensity measures for collapse capacity prediction: choice of optimal spectral period and effect of spectral shape," in Proceedings of 8th National Conference on Earthquake Engineering, San Francisco, CA, USA, April 2006.

[16] F. Zareian and H. Krawinkler, "Simplifi ed performance-based earthquake engineering," Report No. TB 169, John A. Blume Earthquake Engineering Research Center. Department of Civil and Environmental Engineering, Stanford University, Stanford, CA, USA, 2009.

[17] S. W. Han and A. K. Chopra, "Approximate incremental dynamic analysis using the modal pushover analysis procedure," Earthquake Engineering and Structural Dynamics, vol. 35, no. 15, pp. 1853-1873, 2006.

[18] S. W. Han, K.-H. Moon, and A. K. Chopra, "Application of MPA to estimate probability of collapse of structures," Earthquake Engineering and Structural Dynamics, vol. 39, no. 11, pp. 1259-1278, 2010.

[19] B. Shafei, F. Zareian, and D. G. Lignos, “A simplified method for collapse capacity assessment of moment-resisting frame and shear wall structural systems," Engineering Structures, vol. 33, no. 4, pp. 1107-1116, 2011.

[20] FEMA, Seismic Performance Assessment of Buildings, Vol. 58, Prepared by Applied Technology Council as ATC, CA, USA, 2012.

[21] H. Estekanchi, A. Vafaie, and M. Sadeghazar, "Endurance Time method for seismic analysis and design of structures," Journal of Constructional Steel Research, vol. 11, no. 4, pp. 361-370, 2007.

[22] H. T. Riahi and H. E. Estekanchi, "Seismic assessment of steel frames with the endurance time method," Journal of Constructional Steel Research, vol. 66, no. 6, pp. 780-792, 2010.

[23] V. Valamanesh and H. E. Estekanchi, "A study of endurance time method in the analysis of elastic moment frames under 
three-directional seismic loading," Asian Journal of Civil Engineering (Building And Housing), vol. 11, no. 5, pp. 543$562,2010$.

[24] M. Alembagheri and H. E. Estekanchi, "Seismic assessment of unanchored steel storage tanks by endurance time method," Earthquake Engineering and Engineering Vibration, vol. 10, no. 4, pp. 591-603, 2011.

[25] A. Mirzaee and H. E. Estekanchi, "Performance based seismic retrofitting of steel frames by endurance time method," Earthquake Spectra, vol. 31, no. 1, pp. 383-402, 2013.

[26] D. Bernal, "Amplification factors for inelastic dynamicp- $\Delta$ effects in earthquake analysis," Earthquake Engineering and Structural Dynamics, vol. 15, no. 5, pp. 635-651, 1987.

[27] E. Miranda and S. D. Akkar, "Dynamic instability of simple structural systems," Journal of Structural Engineering, vol. 129, no. 12, pp. 1722-1726, 2003.

[28] A. Kaveh and P. Zakian, "An efficient seismic analysis of regular skeletal structures via graph product rules and canonical forms," Earthquakes and Structures, vol. 10, no. 1, pp. 25-51, 2016.

[29] E. B. Williamson, "Evaluation of damage and P - $\Delta$ effects for systems under earthquake excitation," Journal of Structural Engineering, vol. 129, no. 8, pp. 1036-1046, 2003.

[30] G. Kiymaz and E. Seckin, "Behavior and design of stainless steel tubular member welded end connections," Steel and Composite Structures, vol. 17, no. 3, pp. 253-269, 2014.

[31] F. Zareian, H. Krawinkler, L. Ibarra, and D. Lignos, "Basic concepts and performance measures in prediction of collapse of buildings under earthquake ground motions," The Structural Design of Tall and Special Buildings, vol. 19, pp. 167-181, 2010.

[32] H. E. Estekanchi, V. Valamanesh, and A. Vafai, "Application of endurance time method in linear seismic analysis," Engineering Structures, vol. 29, no. 10, pp. 2551-2562, 2007.

[33] M. A Hariri-Ardebili, S. M. Seyed-Kolbadi, and M. Noori, "Response surface method for material uncertainty quantification of infrastructures," Shock and Vibration, vol. 2018, Article ID 1784203, 14 pages, 2018.

[34] S.-K. Lee, J.-H. Park, and M. Byoung-Wook, B.-W. Moon and K.-W. Min, S.-H. Liu and J. Kim, "Design of a bracing-friction damper system for seismic retrofitting," Smart Structures and Systems, vol. 4, no. 5, pp. 685-696, 2008.

[35] B. Tang, X. Lu, L. Ye, and W. Shi, "Evaluation of collapse resistance of RC frame structures for Chinese schools in seismic design categories B and C," Earthquake Engineering and Engineering Vibration, vol. 10, no. 3, pp. 369-377, 2011.

[36] R. K. Mohammadi, M. Mirjalaly, M. Mirtaheri, and M. Nazeryan, "Comparison between uniform deformation method and Genetic Algorithm for optimizing mechanical properties of dampers," Earthquakes and Structures, vol. 14, no. 1, pp. 001-010, 2018.

[37] S. M. S. Kolbadi, H. Davoodian, and S. M. S. Kolbadi, "Evaluation of nonlinear behavior of reinforced concrete frames by explosive dynamic loading using finite element method," Civil Engineering Journal, vol. 3, no. 12, 1198 pages, 2017.

[38] Department of Civil \& Environmental Engineering, Development of Loading Histories for a Testing of Steel Beam-toColumn assemblies, SAC Background Report SAC/BD- 00/10, Stanford University (SAC), Stanford, CA, USA, 2000.

[39] M. Barkhori, S. Maleki, M. Mirtaheri, M. Nazeryan, and S. M. S. Kolbadi, "Investigation of shear lag effect on tension members fillet-welded connections consisting of single and double channel sections," Structural Engineering and Mechanics, vol. 74, no. 3, pp. 445-455, 2020.

[40] M. Heshmati, S. M. S. Kolbadi, and S. M. S. Kolbadi, "Comparison between strain-based vs. Stress-based criteria in seismic performance evaluation of high arch dams," American Journal of Civil Engineering, vol. 3, no. 2-1, pp. 1-8, 2015. 